\title{
A study of cognition and anhedonia in patients with schizophrenia and depression
}

\author{
Akshay Chandurkar ${ }^{1}$, Suyog V. Jaiswal ${ }^{2}$, Vishal A. Sawant ${ }^{3}$ \\ ${ }^{1}$ Ex-resident, ${ }^{2}$ Assistant professor, ${ }^{3}$ Honorary consultant \\ Department of Psychiatry, H. B. T. Medical College and Dr. R. N. Cooper Municipal General Hospital, \\ Mumbai. \\ Corresponding author: Dr. Suyog V. Jaiswal \\ Email-suyogjaiswal@gmail.com
}

\begin{abstract}
Background: The aim of treatment of most psychiatric disorders is the functional improvement but some impairment persists even after remission. Cognitive and hedonic deficits persist even in remission and affect the quality of life in patients with depression and schizophrenia. The study aims to compare cognition, anhedonia and its impact on quality of life in patients with depression and schizophrenia.

Methods: We interviewed 50 consecutive consenting clinically stable patients with schizophrenia (BPRS score < 31) and depressive episode (HDRS score < 08) following up in psychiatry OPD. Montreal Cognitive Assessment (MoCA) was used to assess cognition, Snaith-Hamilton Pleasure Scale (SHAPS) for anhedonia and WHOQOL-BREF for the quality of life in participants.

Results: The mean age of patients with schizophrenia was $41.1 \pm 9.79$ years and that for patients with the Depressive episode was $44.68 \pm 10.32$ years. Cognition in schizophrenia patients was significantly worse $(\mathrm{P}=0.001)$ and anhedonia was better $(\mathrm{P}=0.002)$ than depression, whereas the quality of life was comparable. In Schizophrenia group MoCA and SHAPS scores had a negative correlation $(\mathrm{P}=0.034)$. The quality of life had significant negative correlation with anhedonia in schizophrenia as well as depression patients.

Conclusion: Schizophrenia patients have higher deficits in cognition and depression sees higher hedonic deficit when compared despite being clinical stable and comparable quality of life. Anhedonia impairs quality of life in patients with depression as well as schizophrenia patients but same can't be concluded about the cognitive deficit in depression.
\end{abstract}

Keywords: Anhedonia, Cognition, Quality of life, Schizophrenia, Depression.

(Paper received $-10^{\text {th }}$ November 2017 , Peer review completed $-3^{\text {rd }}$ December 2017)

(Accepted $-6^{\text {th }}$ December 2017)

\section{INTRODUCTION}

Major Depressive disorder and schizophrenia are among the most common mental illnesses. Since the time we have come to terms with the fact that certain disorders which are chronic or episodic may not be amenable for the cure, the focus of treatment has shifted to the improvement in the quality of life by means of controlling the symptoms to as much possible. In the cases of Schizophrenia as well as in many cases of Depression the strategy is to address the distress and symptoms along with restoration of functioning. Along with the characteristic clinical features, the importance of patient's cognition and anhedonia is increasingly being recognized as important areas of intervention in these disorders to improve the quality of life. While some research has suggested that patients with major depression and bipolar disorder are somewhat less impaired in their performance than people with schizophrenia, other studies have found 
little difference in performance [1]. In the case of major depression, the presence of psychotic symptoms has been associated with more severe impairments [2]. In psychiatric disorders, cognitive impairment represents an important issue regarding the differential diagnosis, the success of treatment, rehabilitation and patient's social reintegration [3]. Cognition includes memory, language, orientation, judgment, conducting interpersonal relationships, performing actions, and problem-solving. Cognitive impairment is frequently presented in patients with major depressive disorder [4] and schizophrenia [5]. Cognitive theories of depression posit that people's thoughts, inferences, attitudes, and interpretations, and the way in which they attend to and recall information, can increase their risk for depression. In schizophrenia, to a different extent, cognitive impairment is known to be present in all phases of the disease - prodromal, acute and remission phase [6].

Anhedonia is the inability to derive pleasure in activity or activities that are normally enjoyable to the person. It is considered a core feature of the depressive episode, the patients suffering from depression are not able to find pleasure in the activities they once used to find pleasurable. Similarly, the anhedonia is studied and described in cases of Schizophrenia as well, which yielded mixed results. It is proposed that the hedonic deficit in cases of schizophrenia is more circumscribed [7]. It is also suggested that anhedonia is a symptom of depression but only appears to be a symptom of schizophrenia because it being a component of emotional blunting which is indeed a negative symptom of schizophrenia [8]. Schizophrenia patients experience normal levels of pleasure when directly engaged in an enjoyable activity or consummatory pleasure, but experience disturbances in the experience of pleasure related to future activities, or anticipatory pleasure [9]. The anticipatory pleasure is related to the clinical ratings of anhedonia as well as the functional outcome of it. The hedonic deficit in terms of inability to anticipate the pleasure in an activity may contribute to interpersonal or social isolation, limited social engagement, and other impoverished environments [9].

We, therefore, investigated the components of cognition and anhedonia in patients with schizophrenia and depression to compare them. We also observed the effect of these component these two disorders in terms of quality of life.

\section{METHODOLOGY}

\section{Study design and sample}

This was a cross-sectional single interview study and participants were obtained from the outpatient service of the psychiatry department in a tertiary care municipal teaching hospital, Mumbai. Sample selection was consecutive and 50 patients diagnosed with Schizophrenia and Depressive episode each were interviewed between June 2014 and December 2014.

\section{Ethics}

The study protocol was presented to the institutional ethics committee and was approved before commencement of the study. The patients from psychiatry outpatient department of the hospital fulfilling the inclusion and exclusion criteria were briefed about the study, assured confidentiality and written informed consent was obtained before commencing the interview. Confidentiality was maintained using unique identifiers.

\section{Selection criteria}

Adult follow up patients with a diagnosis of Depressive episode (F32, ICD-10) or Schizophrenia (F20, ICD-10) willing and able to give the written informed consent were included in the study. Only patients who were functional and clinically stable were included in study. Patients with schizophrenia with Brief Psychiatric Rating Scale (BPRS) score 31 or more and patients of depression with Hamilton Depression Rating Scale (HDRS) score 08 or more were excluded from the study. Participants who were diagnosed with any other comorbid psychiatric, neurological illness or suffering from a major disabling illness were excluded. Similarly, Patients of comorbid substance use disorder in dependence pattern other than nicotine and caffeine were excluded from the study. 


\section{Data collection}

All the follow-up patients during the said period were screened and those qualifying the criteria were briefed about the study. After obtaining the written informed consent from willing participants, they were interviewed as per their convenient time and in a single session. Following instrument were used for the purpose of interview -

1. Case record form to record relevant sociodemographic and clinical details.

2. Brief Psychiatric Rating Scale (BPRS): It is one of the most frequently used scales for assessing psychopathology in patients with Schizophrenia. It consists of 18 items and each item is scored on seven-point scale, ranging from 1- not present to 7- extremely severe. Patients with Schizophrenia with score of 31 is suggestive of mildly ill, 41 suggests moderately ill and 53 is indicative of markedly ill. [10] Internal consistency of the scale ranges from 0.76 to 0.79 and interrater reliability of 0.48-0.75 [11].

3. Hamilton Depression Rating Scale (HDRS): It is a multiple-choice questionnaire that clinicians may use to rate the severity of a patient's depression. The scale contains 17 variables and scores less than 8 is normal, 8-13 is suggestive of mild depression, 14-18 of moderate depression, 19-22 of severe depression and more than 22 of very severe depression. Internal consistency is reported 0.83 [12] and validity ranges from 0.65 to 0.90 [13].

4. Montreal Cognitive Assessment (MoCA): It is a scale devised to detect mild cognitive impairment It was validated in the setting of mild cognitive impairment and has subsequently been used in psychiatric patients [14] including Schizophrenia [15]. The Montreal Cognition Scale test is a one-page 30-point test administered in approximately 10 minutes. According to the validation study, the sensitivity and specificity of the Montreal Cognition Assessment for detecting mild cognitive impairment were $90 \%$ and $87 \%$ respectively [16].

5. Snaith-Hamilton Pleasure Scale (SHAPS): It is a scale to assess hedonic experiences and covers four domains: interest/pastimes, social interaction, sensory experience, and food/drink. The items relate to experiences likely to be encountered by most people. The phrasing of the items is expected to overcome the difficulty when a subject is not able to experience the situation currently. Snaith Hamilton Pleasure Rating Scale is a reliable and valid questionnaire to assess hedonic tone in, patient and non-patient populations [17]. The internal consistency of scale is 0.91 with adequate test-retest reliability [18].

6. WHO Quality of Life-BREF (WHOQOL-BREF): It is an abbreviated version of the WHO QOL-100. It is a self-administered instrument. Respondents who have difficulty due to illiteracy can be assisted by an interviewer who reads the question. It takes into consideration physical and psychological factors, social relationships and environmental domains of quality of life and gives subscores on above-mentioned domains ranging from 0 to 100 . Internal consistency of WHO QOL-BREF for Indian patients ranges from 0.63 to 0.84 and it performs well on preliminary tests of validity [19].

\section{Methodology}

Participant's sociodemographic details were noted in specifically designed case record form. The patients of Depressive episode were assessed with HDRS and if score was less than 08 which suggest normal score, they were further interviewed. Similarly, patients with Schizophrenia were assessed on BPRS and those with score less than 31 which is cut off for mildly ill patients were further interviewed. The cut-off scores were kept for both groups to avoid interference of severity of psychopathology with the variables of interest. Since there is no standard cut off for normal score on BPRS, the mildly ill cut off was used for ruling out severe cases. Montreal Cognitive Assessment (MoCA) was used to assess cognition, SnaithHamilton Pleasure Scale (SHAPS) for anhedonia \& WHOQOL-BREF for quality of life in participants. 


\section{STATISTICAL ANALYSIS}

The data thus obtained was analyzed using Statistical Package for Social Sciences (IBM Inc) version 20.0. Descriptive statistics were used to describe the sociodemographic and clinical variables. Chi-square test was used for comparing qualitative variables. Quantitative variables were compared between the groups using Mann-Whitney $U$ test and correlation was done using Spearman rho, since the data failed the test of normality (Shapiro-Wilk test). In this study, a level of significance $(\alpha)$ of $<0.05$ (two-tailed) was taken to consider to result (group difference) statistically significant.

\section{RESULTS}

We studied 50 patients each of Depressive episode and Schizophrenia. The mean age of patients with Schizophrenia was $41.1 \pm 9.79$ years and that for patients with Depressive episode was $44.68 \pm 10.32$ years. The age range for Schizophrenia group was 19 to 60 years and for the Depressive episode group, was 24 to 60 years. Other sociodemographic details were as mentioned in Table 1.

The study variables were compared between Depressive episode and Schizophrenia group and significant difference was noted in cognition and anhedonia score, but all domains of quality of life were comparable between the groups (Table 2).

The correlations were computed separately for Schizophrenia and Depressive episode groups. In Schizophrenia group MoCA and SHAPS scores correlated significantly with each other and most quality of life domains, whereas, in Depressive episode, only SHAPS had significant correlations with quality of life domains (Table 3).

Table 1 - Socio-demographic \& clinical characteristics

\begin{tabular}{|c|c|c|c|c|c|}
\hline \multicolumn{2}{|c|}{ Variable } & \multirow{2}{*}{\begin{tabular}{|c|}
$\begin{array}{c}\text { Schizophrenia } \\
(\mathrm{n}-50)\end{array}$ \\
24 \\
\end{tabular}} & \multirow{2}{*}{\begin{tabular}{|c}
$\begin{array}{c}\text { Depression } \\
(\mathrm{n}-50)\end{array}$ \\
23
\end{tabular}} & \multirow{3}{*}{$\begin{array}{c}\mathrm{df} \\
1\end{array}$} & \multirow{3}{*}{$\begin{array}{c}\mathrm{p} \text { value } \\
0.841\end{array}$} \\
\hline \multirow[t]{2}{*}{ Gender } & Male & & & & \\
\hline & Female & 26 & 27 & & \\
\hline \multirow[t]{4}{*}{ Marital status } & Single & 5 & 6 & \multirow[t]{4}{*}{3} & \multirow[t]{4}{*}{0.655} \\
\hline & Married & 43 & 39 & & \\
\hline & Divorced & 1 & 2 & & \\
\hline & Widowed & 1 & 3 & & \\
\hline \multirow[t]{3}{*}{ Socioeconomic status } & Lower & 45 & 32 & \multirow[t]{3}{*}{2} & \multirow[t]{3}{*}{$0.006^{*}$} \\
\hline & Middle & 2 & 12 & & \\
\hline & Higher & 3 & 6 & & \\
\hline \multirow[t]{4}{*}{ Education } & Primary or less & 15 & 12 & \multirow[t]{4}{*}{3} & \multirow[t]{4}{*}{$0.033^{*}$} \\
\hline & Secondary & 29 & 20 & & \\
\hline & Higher Secondary & 5 & 11 & & \\
\hline & Graduate and more & 1 & 7 & & \\
\hline \multirow{3}{*}{$\begin{array}{c}\text { Current status of } \\
\text { occupation }\end{array}$} & Continuing & 47 & 45 & \multirow[t]{3}{*}{2} & \multirow[t]{3}{*}{0.701} \\
\hline & Retired & 1 & 1 & & \\
\hline & Discontinued & 2 & 4 & & \\
\hline \multirow[t]{2}{*}{ Social support } & Good & 39 & 37 & \multirow[t]{2}{*}{1} & \multirow[t]{2}{*}{0.640} \\
\hline & Poor & 11 & 13 & & \\
\hline
\end{tabular}

( ${ }^{*}$ significant at $<0.05$; All statistics done using the Chi square test) 
Table 2 - Comparison of study variables between the groups

\begin{tabular}{|c|c|c|c|}
\hline \multirow[t]{2}{*}{ Variable } & Schizophrenia (n-50) & Depression (n-50) & \multirow[t]{2}{*}{$\mathrm{P}$ value } \\
\hline & \multicolumn{2}{|c|}{ Median (Interquartile range) } & \\
\hline Cognition (MoCA) score & $28(5.25)$ & $29(2.00)$ & $0.001^{*}$ \\
\hline Anhedonia (SHAPS) Score & $1(1.25)$ & $3(4.25)$ & $0.002^{*}$ \\
\hline Physical QOL & $56(6)$ & $56(13)$ & 0.853 \\
\hline Psychological QOL & $63(19)$ & $63(25)$ & 0.908 \\
\hline Social relationship QOL & $56(20.50)$ & $56(19)$ & 0.386 \\
\hline Environmental QOL & $66(19)$ & $56(25)$ & 0.476 \\
\hline
\end{tabular}

$(\mathrm{p}<0.05 ;$ All statistics done using Mann Whitney U test $)$

Table 3 - Correlation among variables in Schizophrenia and Depression group

\begin{tabular}{|c|c|c|c|c|c|c|c|c|}
\hline & \multicolumn{4}{|c|}{ Schizophrenia } & \multicolumn{4}{|c|}{ Depression } \\
\hline & \multicolumn{2}{|c|}{ Cognition (MoCA) } & \multicolumn{2}{|c|}{$\begin{array}{l}\text { Anhedonia } \\
\text { (SHAPS) }\end{array}$} & \multicolumn{2}{|c|}{$\begin{array}{l}\text { Cognition } \\
\text { (MoCA) }\end{array}$} & \multicolumn{2}{|c|}{$\begin{array}{l}\text { Anhedonia } \\
\text { (SHAPS) }\end{array}$} \\
\hline & $\begin{array}{l}\text { Spearman } \\
\text { rho }\end{array}$ & $\mathrm{P}$ value & $\begin{array}{c}\text { Spearman } \\
\text { rho }\end{array}$ & $\mathrm{P}$ value & $\begin{array}{c}\text { Spearman } \\
\text { rho }\end{array}$ & $\begin{array}{c}\mathrm{P} \\
\text { value }\end{array}$ & $\begin{array}{l}\text { Spearman } \\
\text { rho }\end{array}$ & $P$ value \\
\hline $\begin{array}{l}\text { Cognition } \\
\text { (MoCA) }\end{array}$ & \multicolumn{2}{|c|}{1} & -0.301 & $0.034^{*}$ & \multicolumn{2}{|l|}{1} & -0.096 & 0.509 \\
\hline $\begin{array}{l}\text { Anhedonia } \\
\text { (SHAPS) }\end{array}$ & -0.301 & $0.034^{*}$ & \multicolumn{2}{|c|}{1} & -0.096 & 0.509 & \multicolumn{2}{|c|}{1} \\
\hline $\begin{array}{l}\text { Physical } \\
\text { QOL }\end{array}$ & 0.240 & 0.093 & -0.528 & $<0.001^{*}$ & 0.162 & 0.260 & -0.554 & $<0.001^{*}$ \\
\hline $\begin{array}{l}\text { Psychological } \\
\text { QOL }\end{array}$ & 0.543 & $<0.001^{*}$ & -0.556 & $<0.001^{*}$ & -0.062 & 0.668 & -0.690 & $<0.001^{*}$ \\
\hline $\begin{array}{l}\text { Social relations } \\
\text { QOL }\end{array}$ & 0.314 & $0.027^{*}$ & -0.348 & $0.013^{*}$ & 0.192 & 0.171 & -0.591 & $<0.001^{*}$ \\
\hline $\begin{array}{l}\text { Environmental } \\
\text { QOL }\end{array}$ & 0.609 & $<0.001^{*}$ & -0.636 & $<0.001^{*}$ & 0.139 & 0.337 & -0.714 & $<0.001^{*}$ \\
\hline
\end{tabular}

$\left({ }^{*} \mathrm{p}<0.05\right.$; Spearman rho used in the correlation)

\section{DISCUSSION}

Schizophrenia and depression are among the most common mental illnesses. Along with the characteristic clinical features, the importance of patient's cognition and anhedonia is increasingly being recognized as important areas of intervention in these disorders to improve the quality of life. Many patients suffering from mental disorders require long-term management which means that these features are even more important consideration. Achieving functional recovery over and above clinical remission remains a challenge in treatment of psychiatric disorders. Cognition and anhedonia are the features common in both disorders even during clinical remission, however, the impact of it in both disorders may not be completely similar and is therefore focussed upon here.

\section{Cognition}

Cognitive factors are important and independent predictors of functioning in cases of schizophrenia than psychotic symptoms [20-21]. Similarly cognitive difficulties may persist in patients with depression even after the depressive symptoms have been alleviated [22]. Despite the fact that the main cognitive dysfunctions in depression are related to executive functions, other domains of cognition such as attention, 
processing speed and memory domains are also significantly impaired [22-23]. Neurocognitive deficits play an important role in functional recovery and may compromise the individual's coping abilities and the likelihood of successfully returning to work [24]. When we compared the cognition between patients of schizophrenia and depressive episode, we could find the difference between the cognition scores of two groups, Cognition in patients with schizophrenia was more adversely affected than in patients with depression. Martinez-Aran and Vieta [25] acknowledge the common criticism of cognition research is that cognitive deficits appear to be unspecific but argue that cognitive impairment may be seen as a common pathway after neurological insults due to varied and different causes. The close study of various subdomains of cognition reveals fine differences in the cognitive deficits in different disorders. The individuals with schizophrenia may show deficits in general executive functioning more often and patients of depression may encounter problems with decision making and initiating response [25]. While patients with schizophrenia are significantly impaired in all dimensions of cognition other than visual processing, affective disorder patients have impairment in verbal and visual memory, executive and attention as well as language function [26].

\section{Anhedonia}

In the commonest and simplest understanding, anhedonia is the inability to experience the pleasure. Behaviours associated with anhedonia are lack of engagement in previously pleasurable activities, social withdrawal, lassitude, and avoidance. As cognitive impairment is deficit in cognition, similarly anhedonia is regarded as deficit in the affective domain. Anhedonia is considered as a core feature of schizophrenia as a negative symptom, similarly, it is one of the essential feature to diagnose depression in an individual. Self-reports of emotional experience such as anhedonia can be described under two broad categories: reports of current feelings and reports of non-current feelings [27]. Patients of schizophrenia report higher level of anhedonia than the controls [28] and alteration in outward emotional expression as well [29]. Patients with schizophrenia have more difficulty to anticipating experiences that will be pleasurable, termed anticipatory anhedonia, than experiencing the pleasure of the enjoyable stimulus. [9] Patients with schizophrenia also find it difficult to distinguish overall low mood from inability to experience positive emotion from a pleasurable experience [30]. Anhedonia is also a central symptom in cases of depressive episode and features as a core symptom in diagnostic criteria of depression in ICD-10 as well as DSM-5 apart from low or sad mood. The anhedonia in cases of depression is hypothesized to be a specific form of under arousal [31]. The differentiation between lack of motivation and lack pleasure experience is difficult clinically. [32] As a symptom, the experiential anhedonia associated with melancholic depression may differ from lack of motivation [33]. Our results suggest that anhedonia is associated more with cases of depression than with schizophrenia. What we understand is the anhedonia in cases of depression and schizophrenia are different than each other. The patients of depression may not be able to experience pleasure in positive experience whereas cases with schizophrenia may not be able to anticipate pleasure but very well be able to experience it in positive experiences. However, it may not be easy to distinguish the anticipatory and experiential anhedonia by means of a questionnaire we used and more robust instrument should have been used.

\section{Impact on quality of life}

The study of quality of life (QOL) and the focus on patients' subjective sense of wellbeing is a fairly new phenomenon that has attracted professional attention off late. Research in medicine is dominated by the quest for cures; treating chronic illness as well as helping patients manage long-term impairment received less attention. But when cure is not possible, the quality of life becomes the focus of management. Individuals with cognitive problems may struggle with simple activities of daily living and functioning. This can add to the burden of mental health disorders and can negatively impact quality of life, functioning and employment [34]. The quality of life in patients with schizophrenia and depression was comparable in our sample, suggesting despite the different factors at play in these disorders the impact of these two disorders was on patient's well-being was equivocal.

The patients with schizophrenia have poorer quality of life and it is negatively associated with cognitive functioning [35]. Jaeger and others [24] describe the positive relationship between cognitive deficit and 
functional impairment in patients with diagnosis of major depressive disorder. We were able to replicate the finding of positive correlation between cognition and quality of life in psychological, environmental as well as social relationship domain but not in physical domain. The similar correlation was tested for patients with depression but it was found to be not significant. Similarly, the cognition did not have a significant correlation with anhedonia in cases of depression but a significant negative correlation in cases of schizophrenia. Anhedonia had the negative correlation with all the domains of quality of life in patients with depression as well as schizophrenia. The quality of life is fair in patients with minimal or mild depression may have fair quality of life and those with moderate depression associated with poor quality of life [36]. The quality of life also deteriorates with hedonic deficits especially physical hedonic deficits in patients with schizophrenia and this effect is suggested to be independent of psychopathology or adverse effects [37]. The anhedonia predicts the quality of life in schizophrenia as well as depression and correlates with cognitive deficits of schizophrenia. Cognition, however, does not appear to be significant a contributor to a decreased quality of life in patients with depression but affects certain domains of quality of life in schizophrenia.

\section{Limitations}

Cognition is a complex and multifactorial concept with variable deficits in different disorders. We used a simple instrument to study cognition, which though used previously in both disorders but may not be able to capture the cognitive deficits at comparable level. We specifically focussed on patients who are stable and functional. Two different instruments (HDRS and BPRS) to define it of which it was not possible in schizophrenia patients to conclusively define complete remission of symptoms by means of cut-of used.

\section{REFERENCES}

1. Burdick KE, Goldberg JF, Harrow M, Faull RN, Malhotra AK. Neurocognition as a stable endophenotype in bipolar disorder and schizophrenia. J Nerv Ment Disease 2006;194(4):255-60.

2. Gomez RG, Posener JA, Keller J, DeBattista C, Solvason B, Schatzberg AF. Effects of major depression diagnosis and cortisol levels on indices of neurocognitive function. Psychoneuroendocrinology 2009;34(7):1012-8.

3. Regier DA, Narrow WE, Rae DS, Manderscheid RW, Locke BZ, Goodwin FK. The de facto US mental and addictive disorders service system: Epidemiologic Catchment Area prospective 1-year prevalence rates of disorders and services. Arch Gen Psychiatry 1993;50(2):85-94.

4. Chamberlain SR, Sahakian BJ. Cognition in mania and depression: psychological models and clinical implications. Curr Psychiatry Rep 2004;6(6):451-8.

5. Keefe RSE. Should cognitive impairment be included in the diagnostic criteria for schizophrenia? World Psychiatry 2008;7(1):22-8.

6. Green MF, Kern RS, Heaton RK. Longitudinal studies of cognition and functional outcome in schizophrenia: implications for MATRICS. Schizophr Res 2004;72(1):41-51.

7. Germans MK, Kring AM. Hedonic deficit in anhedonia: support for the role of approach motivation. Personal Individ Diff 2000;28(4):659-72.

8. Romney DM, Candido CL. Anhedonia in depression and schizophrenia: a reexamination. J Nerv Ment Disease 2001;189(11):735-40.

9. Gard DE, Kring AM, Gard MG, Horan WP, Green MF. Anhedonia in schizophrenia: distinctions between anticipatory and consummatory pleasure. Schizophr Res 2007;93(1):253-60.

10. Leucht S, Kane JM, Kissling W, Hamann J, Etschel EVA, Engel R. Clinical implications of brief psychiatric rating scale scores. Br J Psychiatry 2005;187(4):366-71.

11. Hafkenscheid A. Psychometric evaluation of a standardized and expanded Brief Psychiatric Rating Scale. Acta Psychiatr Scand 1991;84(3):294-300.

12. Rush AJ, Trivedi MH, Ibrahim HM, Carmody TJ, Arnow B, Klein DN, et al. The 16-Item Quick Inventory of Depressive Symptomatology (QIDS), clinician rating (QIDS-C), and self-report (QIDS-SR): a psychometric evaluation in patients with chronic major depression. Biol Psychiatry 2003;54(5):573-83.

13. Hamilton M. Hamilton rating scale for Depression (Ham-D). In: Handbook of psychiatric measures. Washington DC: APA; 2000. 
14. Gierus J, Mosiołek A, Koweszko T, Wnukiewicz P, Kozyra O, Szulc A. The Montreal Cognitive Assessment as a preliminary assessment tool in general psychiatry. Validity of MoCA in psychiatric patients. Gen Hosp Psychiatry 2015;37(5):476-80.

15. Wu C, Dagg P, Molgat C. A pilot study to measure cognitive impairment in patients with severe schizophrenia with the Montreal Cognitive Assessment (MoCA). Schizophr Res 2014;158(1-3):151-5.

16. Nasreddine ZS, Phillips NA, Bédirian V, Charbonneau S, Whitehead V, Collin I, et al. The Montreal Cognitive Assessment, MoCA: a brief screening tool for mild cognitive impairment. J Am Geriatr Soc 2005;53(4):695-9.

17. Snaith RP, Hamilton M, Morley S, Humayan A, Hargreaves D, Trigwell P. A scale for the assessment of hedonic tone. The Snaith-Hamilton Pleasure Scale. Br J Psychiatry 1995;167(7):99-103.

18. Franken IHA, Rassin E, Muris P. The assessment of anhedonia in clinical and non-clinical populations: further validation of the Snaith-Hamilton Pleasure Scale (SHAPS). J Affect Disord 2007;99(1):83-9.

19. Skevington SM, Lotfy M, O'Connell KA. The World Health Organization's WHOQOL-BREF quality of life assessment: psychometric properties and results of the international field trial. A report from the WHOQOL group. Qual life Res 2004;13(2):299-310.

20. Bowie CR, Depp C, McGrath JA, Wolyniec P, Mausbach BT, Thornquist MH, et al. Prediction of realworld functional disability in chronic mental disorders: a comparison of schizophrenia and bipolar disorder. Am J Psychiatry 2010;167(9):1116-24.

21. Lewandowski KE, Cohen BM, Keshavan MS, Sperry SH, Öngür D. Neuropsychological functioning predicts community outcomes in affective and non-affective psychoses: a 6-month follow-up. Schizophr Res 2013;148(1):34-7.

22. Bora E, Harrison BJ, Yücel M, Pantelis C. Cognitive impairment in euthymic major depressive disorder: a meta-analysis. Psychol Med 2013;43(10):2017-26.

23. Rock PL, Roiser JP, Riedel WJ, Blackwell AD. Cognitive impairment in depression: a systematic review and meta-analysis. Psychol Med 2014;44(10):2029-40.

24. Jaeger J, Berns S, Uzelac S, Davis-Conway S. Neurocognitive deficits and disability in major depressive disorder. Psychiatry Res 2006;145(1):39-48.

25. Martinez-Aran A, Vieta E. Cognition as a target in schizophrenia, bipolar disorder and depression. Eur Neuropsychopharmacol 2015;25(2):151-7.

26. Reichenberg A, Harvey PD, Bowie CR, Mojtabai R, Rabinowitz J, Heaton RK, et al. Neuropsychological function and dysfunction in schizophrenia and psychotic affective disorders. Schizophr Bull 2008;35(5):1022-9.

27. Robinson MD, Clore GL. Belief and feeling: evidence for an accessibility model of emotional self-report. Psychol Bull 2002;128(6):934.

28. Cohen AS, Dinzeo TJ, Nienow TM, Smith DA, Singer B, Docherty NM. Diminished emotionality and social functioning in schizophrenia. J Nerv Ment Disease 2005;193(12):796-802.

29. Kring AM, Moran EK. Emotional response deficits in schizophrenia: insights from affective science. Schizophr Bull 2008;34(5):819-34.

30. Horan WP, Kring AM, Blanchard JJ. Anhedonia in schizophrenia: a review of assessment strategies. Schizophr Bull 2005;32(2):259-73.

31. Amr M, Volpe FM. Relationship between anhedonia and impulsivity in schizophrenia, major depression and schizoaffective disorder. Asian J Psychiatry 2013;6(6):577-80.

32. Treadway MT, Zald DH. Reconsidering anhedonia in depression: lessons from translational neuroscience. Neurosci Biobehav Rev 2011;35(3):537-55.

33. Treadway MT, Zald DH. Parsing anhedonia: translational models of reward-processing deficits in psychopathology. Curr Dir Psychol Sci 2013;22(3):244-9.

34. Belgaied W, Samp J, Vimont A, R??muzat C, Aball??a S, El Hammi E, et al. Routine clinical assessment of cognitive functioning in schizophrenia, major depressive disorder, and bipolar disorder. Eur Neuropsychopharmacol 2014;24(1):133-41.

35. Savilla K, Kettler L, Galletly C. Relationships between cognitive deficits, symptoms and quality of life in schizophrenia. Aust NZ J Psychiatry 2008;42(6):496-504.

36. Gao K, Sweet J, Su M, Calabrese JR. Depression severity and quality of life of qualified and unqualified patients with a mood disorder for a research study targeting anhedonia in a clinical sample. Asian $\mathrm{J}$ Psychiatry 2017;27:40-7.

37. Ritsner MS, Arbitman M, Lisker A. Anhedonia is an important factor of health-related quality-of-life deficit in schizophrenia and schizoaffective disorder. J Nerv Ment Disease 2011;199(11):845-5.

Acknowledgements - Nil ; Conflict of Interest - Nil; Funding - Nil 